\title{
GLOBALISING DUBLIN: INDICATORS OF AN URBAN SOCIETY IN TRANSITION
}

\author{
Niamh M Moore \\ Department of Geography, University College Dublin, Belfield, Dublin ,IRELAND \\ e-mail: niamh.moore@ucd.ie
}

\begin{abstract}
Globalisation - political, economic or cultural - is controlled from, but is simultaneously shaping, urban places. Much of the recent research on globalisation and urban transformation has focused on the emergence of an international urban system. Within this system, the role and place of Dublin has been highly contested. This is due in part to the unique way in which the city has attempted to re-position itself within a global framework, but is also due to the difficulty in defining what actually constitutes a world city. Friedmann (1986) argues that one of the key characteristics of these places is that they become destination points for both domestic and international migrants, while Sassen (1991) argues that they are typified by significant socio-spatial polarisation. This paper examines some of the ways in which Dublin, a former peripheral city in global terms, is becoming increasingly embedded in the global urban system. It highlights how the city is beginning to exemplify many of the economic, social and cultural characteristics associated with 'world cities' and discusses a suitable framework for understanding this transition.
\end{abstract}

Key words: Dublin, globalisation, cultural economy, polarisation

\section{INTRODUCTION}

Globalisation is perhaps the most over-used and least understood concept in the contemporary world. It is used to describe changes in everything from fashion trends to economic growth. Although a definition is not easy, it is necessary and a range of theorists have made numerous attempts to synthesise what it actually encompasses. Held (1999: 15), a political theorist, has argued that globalisation may be understood as '... spatio-temporal processes of change, which underpin a transformation in the organisation of human affairs by linking together and expanding human activity across regions and continents'. This would suggest that globalisation, although multi-dimensional, is fundamentally geographical and is capable of a) re-writing modernist understandings of how the world is organised and b) interrogating the contemporary validity of traditional core-periphery models of explanation. Short 
(2001: 10) adopts this perspective as he emphasises the spatial significance of this '... process that links people and places, institutions and events around the world'. Sassen (1991) has continued this theme by highlighting the place-boundedness of globalisation, as it is primarily rooted in the urban environment. It is thus pertinent to examine the relationship that exists between this process and urban development, and this is undertaken below with reference to Dublin, Ireland.

\section{CITIES AND GLOBALISATION}

The relationship between cities and globalisation is complex and can be characterised as dialectical: cities are indeed shaped by globalisation, but also have a transformative capacity as they are the control centres from which globalisation evolves. This duality is exemplified through the following themes that highlight the multi-faceted nature of the relationship between globalisation and the urban environment:

- Disproportionate influence: Although not necessarily the largest cities in the world, the economic dominance of London, New York and Tokyo within the global economy has rendered them premier world cities in the international urban hierarchy. Global economics has thus played the key role in shaping the global urban hierarchy.

- Inter-urban competition: Greater capital mobility due to improved telecommunications and the desire of private investors to globalise their sphere of influence has resulted in greater competition between cities for a finite set of economic resources. The result has been a shift in urban governance from a more managerial to entrepreneurial approach (Harvey, 1989).

- Urban development tools: Given that most cities are competing to attract mobile international capital in terms of footloose hi-tech industries, employment, institutions, events (conventions and spectacles) and tourism, a standard international set of 'successful' urban development tools has emerged. This involves combining successful marketing with the provision of generous economic incentives, and locally-specific attributes such as a low cost base.

- Spatial restructuring: A changing world economic structure has resulted in largescale urban restructuring. The dominance of the international service industry has facilitated the emergence of new districts within cities and the expansion of 'world-city' functions at the expense of former industrial / manufacturing activity.

- Increased cosmopolitanism: Increased commonalities between large metropolises are becoming more apparent as a global metropolitan culture emerges. Similarities are evident in the built environment, specific lifestyles, policy instruments and dynamic business atmospheres. Behrman and Rondinelli (1992) argue that globalisation puts pressure on cities to develop their specific cultures in ways that attract business, investment and high-tech professionals (as noted above) and that convince their own residents and entrepreneurs to remain. However this hybridisation of society has also occurred spontaneously as a by-product of mass movements of people to cities for a variety of reasons. 
If these trends illustrate some of the links between globalisation and urbanisation, is it then possible to deduct that the operation of these processes in a particular place is indicative of the power of globalisation in particular urban areas? Although the exact nature and extent of these processes varies over space, the ultimate aim is the same: to maximise the international significance of local places and aim for 'world city' status. Patrick Geddes first coined the phrase in 1915, when he defined world cities as places where the world's business is done. Today there is a whole range of much more detailed definitions of world cities, including those by Friedmann (1986) and Sassen (1991) that build on the original definition. Friedmann (1986) argues that three 'world cities' constitute the major sites for the concentration and accumulation of international capital, the centre of corporate headquarters, international finance, global transport and communications, and high level business services and a point of destination for both domestic and international migrants. Sassen (1991) likewise argues that New York, London and Tokyo are economic nodes, sites of innovation and in common with Mollenkopf and Castells (1992) she argues that they are characterised by increased spatial polarisation. Other authors (Kim \& Short, 1999) argue for a broadening of the debate to consider the impact of globalisation on cities other than the 'Big Three', a trend that is becoming increasingly evident. In many discussions of the global urban system, the dominance of the three cities noted above is being questioned as cities like Paris and Frankfurt rival them in terms of both linkages and particular functions. Although not on a par with cities like those noted above, medium-sized cities like Dublin who actively seek out international investment capital are increasingly exemplifying the characteristics that the authors above attribute to world cities. These new 'wannabe world cities', 'world cities on the edge' or the world's next great international cities' are in many cases sited in, what have been traditionally considered, semi-peripheral or peripheral locations. However, given the newfound opportunities provided by the mobility of international finance, cities like Dublin are becoming progressively more competitive and aggressive on the global stage with profound implications at the local level.

\section{WORLD CITYNESS}

Accurately measuring how embedded particular places are in the global urban system is an almost impossible task, but two methods have been designed to give some sort of indication on this matter. The first analyses the linkages of particular cities, while the second examines the functions of these places. One of the problems of using the former methodology is the difficulty in obtaining data. However Short \& Kim (1999) suggest the utilisation of inter-city information on international airflows. By examining airline data and particularly the number of daily non-stop flights, the extent of transport linkages or the relative accessibility of a particular place may be gauged. Adopting this methodology and considering travel patterns to and from Dublin Airport should provide a general indication of trends regarding the connectivity of the city. In 2002, the airport had a throughput of 15.1 million passengers, a $5 \%$ increase on the previous year, and serviced 74 destinations by scheduled departures. In comparison with London or New York, this is not a particularly high number. However, the dramatic increase in recent years in the range of destinations that are 
accessible from Dublin provides evidence to suggest that Dublin is becoming increasingly interconnected on the global stage. However this methodology does not provide enough evidence to conclusively prove this to be case.

Utilising the second methodology noted above, an assessment of urban functions, the Globalisation and World Cities Research Centre at Loughborough University, UK has produced a rank order of cities in terms of their importance for particular activities and unsurprisingly London, New York and Tokyo emerge at the top of almost all the scales (Beaverstock et al., 1999). However, apart from identifying places we would already assume to be the key 'world cities', it is almost impossible to draw any clear conclusions about cities further down the scale as their relative importance varies depending on the function measured. Dublin provides an excellent example of this. In terms of command functions within the global economy, this city most definitely has no key role to play. However, if an alternate measurement technique - network functions - is adopted, a very different picture emerges. Taylor (2003) concludes that Dublin is the ninth most globally networked city within the EU and the thirtieth most connected at a world scale. Table 1 below shows the top 10 European Cities for Network Power, within which Dublin is quite clearly a dominant player. The explanation for this ranking is directly attributable to government urban policy, which facilitated the development of the International Financial Services Centre as part of a waterfront renewal project in Dublin's Docklands in the early 1990s. Although the establishment of this centre formally encouraged the economic internationalisation of the city and is the main causative effective of this ranking, the impact of globalisation in Dublin extends far beyond the purely financial.

Table 1: Europe's cities as Global Network Powers

\begin{tabular}{|c|l|}
\hline \multicolumn{2}{|l|}{ Network power } \\
\hline World rank & Gateway City \\
\hline 2 & Moscow \\
3 & Zurich \\
7 & Prague \\
9 & Brussels \\
12 & Dublin \\
14 & Milan \\
23 & Warsaw \\
24 & Barcelona \\
25 & Madrid \\
26 & Lisbon \\
\hline
\end{tabular}

Source: Taylor, 2003

\section{HOW GLOBALISED IS DUBLIN?}

In the recently published AT Kearney/Foreign Policy magazine Globalisation Index, Ireland emerged for the second year running as the most globalised country in the world. 
However, this was not only attributable to economic factors but also to personal/societal factors. Although the methodologies already outlined above tell us something of the ranking of cities within the global urban system according to specified criteria, they do not give any indication of the impacts that globalisation has at the intra-urban level. In an attempt to redress this, Smith and Timberlake (1995) have constructed a typology highlighting particular impacts of globalisation across a range of fields. Illustrated in Table 2 with reference to particular examples, the model comprises four functional flows: economic, political, cultural and social, and three forms that these may take: human, material and information. Three elements of this typology, as highlighted below, will now be examined briefly.

Table 2: Understanding globalisation

\begin{tabular}{|l|l|l|l|}
\hline $\begin{array}{l}\text { Function } \\
\text { Form }\end{array}$ & Human & Material & Information \\
\hline Economic & Labour & Capital & Global forum (G8) \\
\hline Political & International governors & Institutions & Policy documents \\
\hline Cultural & Migration & Paintings, exhibitions & Internet, advertising \\
\hline Social & Interaction (tourism) & Organisations & News, media, TV \\
\hline
\end{tabular}

Source: Compiled by author after Smith and Timberlake (1995)

One of the major difficulties with such a typology is the difficulty in measuring the significance of each of these factors, particularly in terms of the 'information' categorisation. However, in Dublin the significance of human and material flows are quite readily apparent, measurable to some extent, and combined with anecdotal evidence provide a clear indication of how increasingly globalised the city is becoming.

\section{HUMAN ECONOMIC AND CULTURAL FLOWS}

With strict immigration procedures in most developed countries, increasingly so since September $11^{\text {th }} 2001$, it is relatively easy to measure human flows, one of the hallmarks of globalisation. In Ireland, the challenges posed by unprecedented levels of migration have been topping the public agenda for a number of years and there are excellent statistics available from official sources related to this topic. Even to the casual observer, Irish society has undergone a dramatic shift in recent years from being an almost entirely Caucasian, Christian society to one characterised by a more mixed ethnic profile with most of the change centred in the capital region. The recently published preliminary reports of the 2002 Census highlight a number of interesting statistics that underscore the radical changes that are occurring. In Dublin, traditionally viewed as the capital of Catholic Ireland, the third largest religious group is now Muslim. 6\% of the population of Ireland are now nonnationals and of these, only $51 \%$ are from the traditional sources of emigration such as the UK and America. Almost 20\% are from Africa and Asia, non-traditional sources of emigra- 
tion to Ireland indicative of the changing significance of Ireland at a global level (Central Statistics Office, 2003). The general upward trend in migration from these continents highlights the increasing importance of Ireland, and Dublin in particular, as a destination point for international migration, borne out by the dramatic increase in illegal immigration and in the number of asylum-seekers entering the State (Figure 1). Although not huge in absolute terms, this has been a radical cultural shift for Ireland as it has only recently become a country of immigration rather than emigration. The majority of those entering the state have been accommodated in the Greater Dublin Area, although the government are beginning to engage in a controversial and not necessarily successful policy of dispersal. This has been a significant factor in altering the ethnic and social make-up of the Dublin region, as permission to work is denied to asylum seekers until their application has been processed.

Figure 1: Numbers of asylum-seekers entering Ireland, 1997-2002

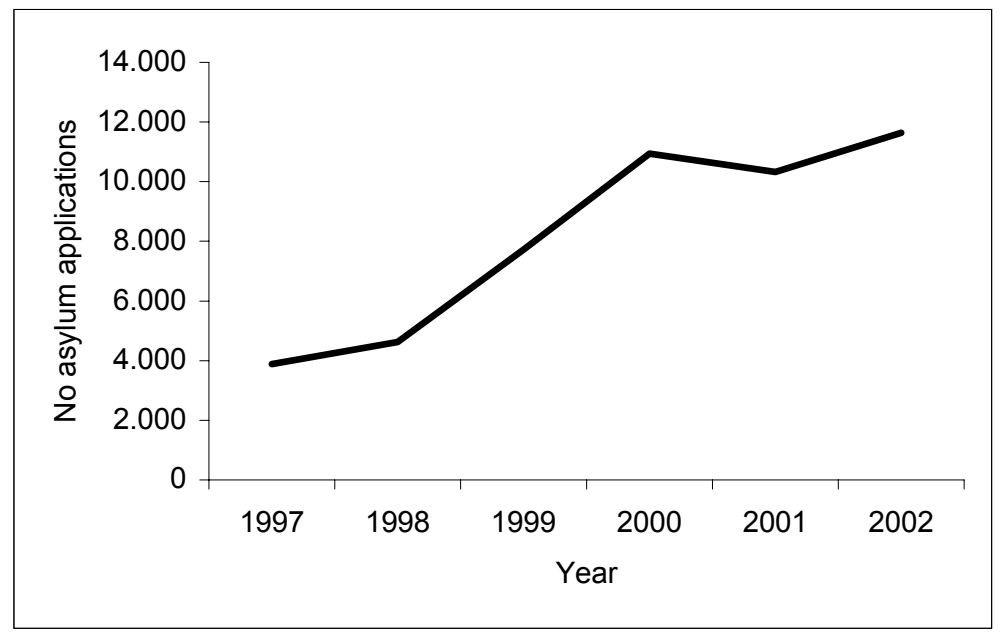

Source: Compiled from Dept of Justice, Equality and Law Reform, 2003

The one difficulty with depending on this set of statistics alone is that it does not explain the increasing plurality of the labour force. Figure 2 below highlights the increasing trend towards the internationalisation of the Irish workforce, which has occurred in part as a response to skills shortages in particular sectors of the economy but also because of specific marketing activities undertaken by the Irish government to target specific professions. The most obvious example of this is in the nursing profession, where a large number of nurses from the Philippines have been employed to redress staff shortages in Dublin hospitals.

Analysis of work visa applications to the employment authorities highlights a clustering of international labour in the capital region. The most recent figures indicate that $38.4 \%$ of all new work permits and $40.4 \%$ of permits renewed have been issued to those living in Dublin. This trend towards a more ethnically diverse population in the capital city 
is borne out by analysing the place of birth of Dublin residents as evident from the 1996 Census results:

- $16 \%$ of Dublin population born in another county

- $7.25 \%$ of Dublin population born outside Ireland

- $31 \%$ of Irish residents of US birth lived in Dublin

- $51 \%$ of Irish residents born outside Great Britain, Europe or USA live in Dublin

Figure 2: New work permits issued, $1999-2003$

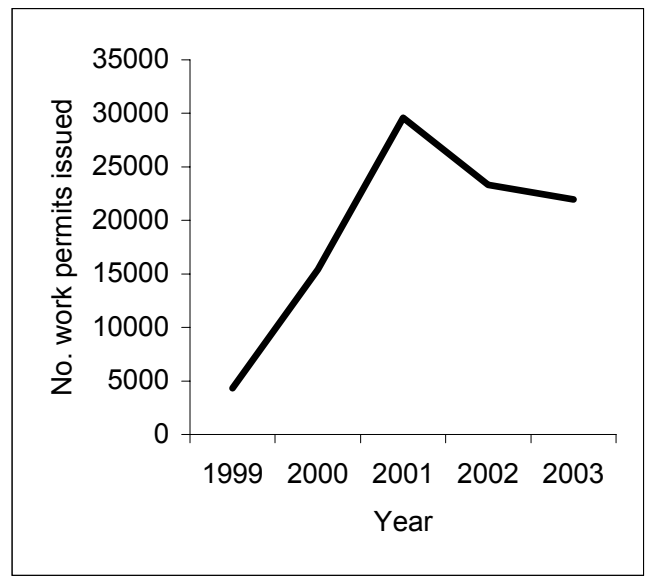

Source: Compiled from Dept of Enterprise, Trade and Employment, 2003

The most obvious physical manifestation of this change has been an explosion in the number of ethnic shops, restaurants and service facilities in the inner-city, catering to specific populations. The terms 'Little Africa', 'Middle Eastern' quarter and the 'Little Caribbean' are increasingly being used about particular parts of the urban core. In summary, it can be argued that Dublin has remained an important point for national migration, while becoming an attractive location for international migrants, exemplifying one of the key characteristics of a 'world city' as defined by Friedmann (1986) and Sassen (1991).

\section{MATERIAL ECONOMIC FLOWS}

Similar trends towards convergence with the 'world city' model appear to be occurring when one considers the changing patterns of material economic flows, illustrated by the flow of global investment capital into Dublin. As mentioned earlier in this paper, one of the key drivers of this development has been the International Financial Services Centre. Established in the late 1990s, as part of an urban renewal programme in the Dublin docklands, this centre became the 'hotpsot' or 'engine' of the Celtic tiger boom in the 1990s. It succeeded in doing so by exploiting a niche in back-office financial operations and telecommuni- 
cations services as has been well-documented by other authors (Murphy, 1998). Primarily due to the existence of this centre, Dublin has garnered itself a reputation as a major gateway city in Europe and has scored highly in global rankings of network power. The following key statistics highlight the importance of this project to the globalisation of Dublin:

- Direct employment: 11,000 jobs

- $\quad$ Stand Alone Banking and Asset Finance Operations: 139

- Agency Treasury Companies: 190

- Multinational Treasury Centres: 389

Table 3 below indicates the broad nature of the financial services activities occurring at the IFSC and the home country of the parent company.

Table 3:Analysis of IFSC stand-alone operations

\begin{tabular}{|l|c|c|c|c|c|c|}
\hline Origin & $\begin{array}{l}\text { Banking and } \\
\text { asset finance }\end{array}$ & $\begin{array}{l}\text { Mutual } \\
\text { funds }\end{array}$ & Treasury & Insurance & $\begin{array}{l}\text { Securities, tra- } \\
\text { ding, and others }\end{array}$ & Total \\
\hline USA & 18 & 21 & 22 & 20 & 25 & 106 \\
\hline IRL & 18 & 2 & 10 & 9 & 47 & 86 \\
\hline UK & 4 & 24 & 9 & 15 & 7 & 59 \\
\hline GER & 20 & 4 & 6 & 7 & 6 & 43 \\
\hline ITA & 18 & 4 & 1 & 12 & 4 & 39 \\
\hline JPN & 12 & 0 & 0 & 2 & 1 & 15 \\
\hline NL & 3 & 3 & 5 & 3 & 0 & 14 \\
\hline CAN & 4 & 3 & 2 & 4 & 1 & 14 \\
\hline SWE & 0 & 1 & 3 & 6 & 0 & 10 \\
\hline DK & 5 & 2 & 1 & 1 & 0 & 9 \\
\hline BEL & 6 & 0 & 2 & 0 & 0 & 8 \\
\hline SWITZ & 0 & 0 & 1 & 5 & 0 & 6 \\
\hline Others & 31 & 13 & 11 & 8 & 18 & 81 \\
\hline Total & $\mathbf{1 3 9}$ & $\mathbf{7 7}$ & $\mathbf{7 3}$ & $\mathbf{9 2}$ & $\mathbf{1 0 9}$ & $\mathbf{4 9 0}$ \\
\hline
\end{tabular}

Source: DDDA, 1999

Almost $20 \%$ of the total companies operating in this area have a home base in North America, while over 16\% come from regions outside the Atlantic axis. Physically, the impact on the city has been phenomenal as a former, derelict, industrial wasteland has been transformed into an island of international corporate power within a growing urban core. However, the development of this centre has not occurred without negative repercussions. Originally aimed at rejuvenating the local economy and redressing the many social problems that prevailed in the docklands area, the area has now become a pawn in the game of global capital. Through the 1990s, the impact of this major project on the local population was negligible, with the exception of increasing traffic flows and the prices of everyday goods in the local shops. A new residential base comprising numerous 'gated communities' was established adjacent to the IFSC, catering to the requirements of the financial services and other socially similar employees (Moore, 2001). Levels of interaction between the old and 
new residents were non-existent, with the exception of those who gained employment in low-paid jobs, providing cleaning and other services to the hotels and service outlets. Thus, the rejuvenation of the Custom House Docks area in Dublin has followed the international trend of increasing socio-spatial polarisation in a newly-developed district. This part of Dublin exhibits the 'dual' personality that Mollenkopf and Castells (1992) associate with a socially and economically restructured New York and the growing income and social divides that Sassen (1991) considers a standard outcome of economic globalisation within the city. Traditional core-periphery models are re-written and called into question as cities become increasingly split between the haves and have-nots. In Dublin City, economic and physical restructuring has widened socio-economic gaps while simultaneously bringing different groups of people spatially closer, as new patterns of centralisation and marginalisation, more readily associated with international difference, are played out at the urban scale.

\section{CONCLUSION}

This paper has examined many elements of transition in Dublin, indicative of the manner in which this medium-sized city has begun to exhibit social, economic, physical and cultural trends attributed by other authors to 'world cities'. It is therefore increasingly possible to argue that these factors are not characteristic of the great world cities alone, but are simply expressions of the impact of globalisation on cities in general. Although this paper has focused on the human and material economic flows that have contributed to Dublin's transformation over the last decade, it would be a mistake to consider them the only forms that are contributing to the increased interconnectedness of the Irish capital in the global urban system. One of the most recent ways in which the city has strived to improve its position on the world stage is through the attraction of large-scale cultural events. As Dublin now competes with other cities for a limited amount of international investment capital, city authorities have become more entrepreneurial and are pro-actively engaged in urban promotion to market the city not only as a place to do business, but also as an attractive place to work, visit and live. Haider (1992) has defined this type of activity as a 'place war' between cities and in the case of Dublin, it has resulted in numerous bids for high-profile cultural events including the Special Olympics, Euro 2008 football championships (unsuccessful), and the Cutty Sark Tall Ships race. In an attempt to successfully compete in a rapidly evolving and unpredictable global urban system, Dublin has attempted to combine its reputation as a place to do international business with a multi-dimensional cultural identity. Balancing these global requirements against local needs will be the biggest challenges facing policymakers in the city of tomorrow, but will be imperative in order to stem the increasing socio-cultural tensions that are emerging in Ireland's capital city.

\section{References}

Beaverstock, J. et al. 1999: A roster of world cities, Cities, 16(6) 445-458. 
Behrman, J. \& Rodinelli, D., 1992: The cultural imperatives of globalisation: urban economic growth in the $21^{\text {st }}$ century. Economic Development Quarterly, 6(2), 115-126.

Central Statistics Office 2003: Census 2002: Preliminary Report. Dublin: Stationery Office

DDDA 1999: Annual Report and Accounts 1998. Dublin: Dublin Docklands Development Authority

Department of Enterprise, trade and employment (2003) www.entemp.ie. Accessed August $5^{\text {th }} 2003$.

Department of Justice, Equality and Law Reform (2003), www.justice.ie. Accessed August $5^{\text {th }} 2003$.

Friedmann, J. 1986: 'The World City Hypothesis', Development and Change, 17, 69-83

Harvey, D. 1989: 'From managerialism to entrepreneurialism: The transformation in urban governance in late capitalism', Geografiska Annaler. 71B(1), 3 - 17.

Held, D. et al. 1999: Global transformations: politics, economics and culture. Oxford: Polity Press

Mollenkopf, J. and Castells, M. 1992: Dual City: Restructuring New York. New York: Sage.

Moore, N. 2001: The Celtic Tiger and the Welsh Dragon: Urban redevelopment in Dublin docklands and Cardiff Bay, 1987-2001. Unpublished PhD Thesis, University College Dublin.

Murphy, L. 1998: Financial engine or glorified back office? Dublin's International Financial Services Centre going global'. Area, 30 (2), 157 - 165.

Sassen, S. 1991: The global city: New York, London, Tokyo. Princeton: Princeton University Press

Short, J.R. \& Kim, Y. 1999: Globalization and the city. Harlow: Longman

Short, J.R. 2001: Global dimensions: space, place and the contemporary world. London: Reaktion

Smith, D. \& Timberlake, M. 1995: Conceptualising and mapping the structure of the world's city system, Urban Studies, 32(2), 287-302.

Taylor, P. 2003: European Cities in the World City Network, GaWC Research Bulletin 105, Loughborough: Globalisation and World Cities Research Centre. 